\title{
LA LIMITACIÓN DE LAS BASES IMPONIBLES DEL IBI RÚSTICO PARA LAS COOPERATIVAS AGRARIAS EN EL RÉGIMEN FISCAL DE COOPERATIVAS Y SU NECESARIA REFORMA ${ }^{I}$
}

\author{
POR \\ Sergio MARÍ VIDAL ${ }^{2}$
}

\section{RESUMEN}

Las sociedades cooperativas en España, al igual que en otros países, vienen gozando de unos beneficios tributarios en virtud de la decidida protección que el legislador les ha querido conferir. La normativa actualmente vigente en España es la Ley de Régimen Fiscal de Cooperativas (LRFC), que establece diferentes niveles de beneficios en función del grado de protección que otorga a la cooperativa. En el caso de las cooperativas agrarias se establecen ciertos requisitos para alcanzar el mayor grado de protección, entre los que se encuentra que la base imponible del Impuesto sobre Bienes Inmuebles (IBI) correspondiente a los bienes de naturaleza rústica, dentro del ámbito geográfico de actuación de la sociedad, no exceda de $39.065,79 €$.

En el presente trabajo se analiza si la no actualización de ese límite desde la promulgación de la LRFC en 1990 puede suponer un problema para el cumplimiento del mismo por parte de las cooperativas agrarias para seguir gozando de la especial protección.

En este sentido se pondrá de manifiesto cómo los valores catastrales (que determinan la base imponible del IBI de los inmuebles de naturaleza rústica) se han venido actualizando

\footnotetext{
${ }^{1}$ Este trabajo se enmarca dentro de un Convenio de Colaboración firmado con la Confederación de Cooperativas Agrarias de España.

${ }^{2}$ Profesor Titular de Universidad. Centro de Investigación en Gestión de Empresas (CEGEA). Universidad Politécnica de Valencia.smari@cegea.upv.es
}

REVESCO No 104 - Primer Cuatrimestre 2011 - ISSN: 1885-8031 - www.ucm.es/info/revesco

DOI: 10.5209/rev_REVE.2011.v104.6

Fecha de recepción: 29/06/2010

Fecha de aceptación: 15/11/2010 
anualmente, con el consiguiente incremento de los mismos y por tanto se hace necesaria la reforma del límite fijado en la LRFC.

Palabras Clave: Fiscalidad de cooperativas, Actualización valor catastral.

\title{
LIMITATION OF THE TAX BASE ON THE LAND TAX FOR AGRICULTURAL COOPERATIVES IN THE COOPERATIVE TAX SYSTEM, AND IT'S NECESSARY REFORM.
}

\begin{abstract}
Cooperatives in Spain, as in other countries, have been enjoying tax benefits under the protection that legislator intended to confer on them. The legislation currently in force in Spain is the Cooperative Tax Systme (CTS), which provides different levels of benefits depending on the degree of protection afforded to the cooperative. In the case of agricultural cooperatives certain requirements are established to achieve the highest degree of protection, which is the Tax Base on the Land Tax. It can't exceed $€$ 39,065.79.
\end{abstract}

In the present paper we analyze whether the failure to update this limit since the publication of the CTS in 1990 can be a problem for the performance thereof by the agricultural cooperatives to continue to enjoy special protection.

In this sense we will show how cadastral values (which determine the tax base of the Land Tax) have been updated annually, with their consequent increase and therefore it becomes necessary to reform this limit in CTS.

Keywords: Taxation on cooperatives. Cadastral value readjustement. 


\section{INTRODUCCIÓN}

Las sociedades cooperativas en España gozan de un régimen de especialidades tributarias, la Ley 20/1990 de Régimen Fiscal de Cooperativas (LRFC), que las diferencian del resto de sociedades. Esta Ley constituye un conjunto de disposiciones que regulan técnicamente la aplicación de las normas tributarias de carácter general en este tipo de sociedades, atendiendo a sus especificidades que se derivan del hecho de su diferenciación en su regulación societaria, además de establecer un conjunto de bonificaciones fiscales para las cooperativas que cumplan determinados requisitos (Juliá Igual J.F., y Server Izquierdo R.J., 1996).

Este tratamiento fiscal especial parece lógico si recordamos que es España uno de los países donde se recoge el fomento cooperativo en el artículo 129.2 de su constitución (De Luís Esteban J.M., 1987), y que en el conjunto de países de la U.E. las cooperativas en determinados supuestos y actividades gozan en mayor o menor medida de una serie de beneficios o incentivos fiscales. Pero no es esta la única razón que justifica este tratamiento. También nos encontramos con razones históricas o tradicionales. No en vano, la existencia de normas tributarias de específica aplicación a las cooperativas se remonta a los primeros años del siglo XX constituyendo la Ley de 27 de marzo de 1900, reguladora de la Contribución de Utilidades de la Riqueza Mobiliaria, la primera norma que otorga determinados beneficios fiscales a las cooperativas de crédito, producción y consumo de las clases obreras al eximirles del pago de este tributo (García Calvente Y., y Garijo M.R., 2005). En relación con las cooperativas agrarias, la Ley de Sindicatos Agrícolas de 1906, que puede considerarse el origen del cooperativismo agrario en España preveía determinadas ventajas fiscales para estas entidades (Marí Vidal S, y Juliá Igual J.F., 2001).

La Ley de RFC establece una clasificación en orden al grado de protección fiscal de las cooperativas:

a) Cooperativas protegidas, que constituyen el primer grado de protección e implican una serie de beneficios tributarios.

b) Cooperativas especialmente protegidas, a las que se atribuye el mayor grado de protección fiscal y más ventajas fiscales. 
No obstante, también resulta de aplicación para las cooperativas no protegidas, que son las que incurren en causa de pérdida de la protección y a las que únicamente se les aplicará el conjunto de normas técnicas de aplicación del Impuesto sobre Sociedades a cooperativas, tributando al tipo general por la totalidad de sus resultados.

Entre los incentivos fiscales que otorga la norma nos encontramos beneficios en el Impuesto sobre Sociedades, tributos locales y del Impuesto sobre Transmisiones Patrimoniales y Actos Jurídicos Documentados (Mas Ortiz A. y Cintado Canto F.J, 2007). No es el objetivo de este trabajo enumerar estos beneficios, por lo que únicamente destacaremos los más importantes:

En relación con el Impuesto sobre Sociedades, las cooperativas protegidas aplicarán un tipo de gravamen del $20 \%$ para los resultados clasificados como cooperativos, debiendo aplicar el tipo general al resto de resultados. Además, pueden aplicar la libertad de amortización para los activos fijos nuevos adquiridos en los tres primeros años desde su inscripción en el Registro. En el caso de las cooperativas especialmente protegidas, además de los beneficios ya mencionados disfrutan de una bonificación del 50\% de la cuota íntegra.

En relación con el Impuesto sobre Transmisiones Patrimoniales y Actos Jurídicos Documentados, las cooperativas protegidas disfrutan de la exención en este impuesto por determinados actos tasados que pueden realizar a lo largo de su vida, ampliándose este listado en el caso de cooperativas especialmente protegidas.

Finalmente, en relación con los beneficios en los tributos locales, tanto las cooperativas protegidas como las especialmente protegidas tienen determinadas exenciones en impuestos como el Impuesto de Actividades Económicas, en los casos en los que sea de aplicación, el Impuesto sobre Bienes Inmuebles, el Impuesto sobre Vehículos de Tracción Mecánica y otros. No obstante, la aplicación de estos impuestos puede depender del tipo de cooperativa (agraria, explotación comunitaria de la tierra, viviendas, etc.) o en algunos casos del ente local del que dependa dicho impuesto (García Calvente Y., y Garijo M.R., 2005).

Las sociedades cooperativas, que se ajusten a los principios y disposiciones de la Ley General de Cooperativas o las de las comunidades autónomas, tendrán la consideración de fiscalmente protegidas siempre que no incurran en ninguna de las causas de pérdida de dicha 
condición (art. 13 LRFC), que fundamentalmente se refieren al cumplimiento del régimen económico de la legislación cooperativa, como puede ser lo referente a los Fondos de Reserva Obligatorio y Educación y Promoción, aportaciones a capital social, retornos, y causas de disolución en que toma los límites de la Ley General de Cooperativas.

La condición de especial protección, se reduce a determinadas clases de cooperativas en las que además se cumplen ciertas condiciones relativas a su base social, esto es, a la actividad y condición económica de sus socios.

Las cooperativas que pueden en principio gozar de la especial protección son, de acuerdo con el art. $7^{\circ}$ de la LRFC:

- Cooperativas de trabajo asociado.

- Cooperativas agrarias.

- Cooperativas de explotación comunitaria de la tierra.

- Cooperativas del mar.

- Cooperativas de consumidores y usuarios.

Centrándonos en el caso de las cooperativas agrarias, para gozar de la calificación de especialmente protegidas deben cumplir con las condiciones siguientes, que se refieren al límite de operaciones con terceros y a que sus socios sean básicamente pequeños y medianos agricultores (Juliá Igual J,F. et al, 1999):

- En cuanto al límite de las operaciones con terceros, se fijan en el 5\%, o hasta el $40 \%$ si se indica expresamente en los Estatutos. Por Ley 24/2005 de reformas para el impulso a la productividad se excepciona el suministro de gasóleo B a terceros no socios sin límites y sin perder la condición de especialmente protegida. No obstante, está pendiente la reforma de este último punto, como consecuencia de la Decisión de la Comisión de 15 de Diciembre de 2009 relativa a las medidas de apoyo al sector agrícola aplicadas por España tras la subida del coste del combustible.

- En cuanto a sus socios, sólo lo pueden ser las personas físicas titulares de explotaciones agrícolas, forestales o ganaderas o mixtas situadas dentro del ámbito geográfico de actuación fijado en sus estatutos, otras cooperativas agrarias y de explotación comunitaria de la tierra, SAT, entes públicos o sociedades donde 
participen mayoritariamente entes públicos, asimismo las comunidades de bienes o derechos que estén integradas por personas físicas.

- En relación con el nivel económico de la actividad de sus socios, se fija como límite que la base imponible del Impuesto sobre Bienes Inmuebles (IBI) correspondiente a los bienes de naturaleza rústica, dentro del ámbito geográfico de actuación de la sociedad, no exceda de 6.500 .000 ptas. $(39.065,79 €)$; cuando los socios sean a su vez sociedades cooperativas o SAT el límite se refiere a cada uno de sus respectivos socios. No obstante pueden existir algunos socios que superen dicho límite, siempre y cuando no exceda el conjunto de sus bases del $30 \%$ de la suma de las del resto de socios.

- En el caso de la ganadería independiente, las ventas individuales de los socios no pueden superar el límite establecido para poder acogerse al método de Estimación Objetiva Singular en el Impuesto sobre la Renta de las Personas Físicas (IRPF), admitiéndose también la concurrencia de socios por encima de dicho límite, siempre y cuando el conjunto de las ventas de los que superen éste no exceda del $30 \%$ de la suma de los restantes. Lógicamente la referencia a la Estimación Objetiva Singular debe entenderse hecha al Régimen de Estimación Objetiva que la sustituye desde la aprobación la Ley 40/1998 del IRPF.

De los requisitos antes mencionados nos centraremos únicamente en el relacionado con las bases imponibles del IBI, por entender que es el que puede resultar discriminatorio para las cooperativas al establecer un importe fijo que no puede sobrepasarse. El resto de requisitos son fijados como porcentajes o como límites fijados en otras normativas que pueden, y de hecho se actualizan a través de las mismas.

Así pues, el objetivo que nos planteamos en este trabajo es comprobar si la no actualización del límite fijado por la normativa de régimen fiscal de cooperativas puede tener incidencia en la clasificación fiscal de las cooperativas agrarias, de modo que una cooperativa especialmente protegida pueda perder esa especial protección por sobrepasar este límite. 


\section{DETERMINACIÓN DE LA BASE IMPONIBLE EN EL IMPUESTO SOBRE BIENES INMUEBLES}

El Impuesto sobre Bienes Inmuebles es un tributo directo de carácter real que grava el valor de los bienes inmuebles en los términos establecidos en la Ley Reguladora de las Haciendas Locales (Real Decreto Legislativo 2/2004 de 5 de marzo, por el que se aprueba el texto refundido de la Ley Reguladora de las Haciendas Locales).

El artículo 66 de de esta misma Ley establece que la base imponible de este impuesto estará constituida por el valor catastral de los bienes inmuebles, que se determinará, notificará y será susceptible de impugnación conforme a lo dispuesto en las normas reguladoras del Catastro Inmobiliario.

El valor catastral, de acuerdo con lo establecido en el artículo 22 del Real Decreto Legislativo 1/2004 por el que se aprueba el Texto Refundido de la Ley del Catastro Inmobiliario, es el determinado objetivamente para cada bien inmueble a partir de los datos obrantes en el Catastro Inmobiliario y está integrado por el valor catastral del suelo y el valor catastral de las construcciones.

Asimismo, el artículo 32 de este RDL 1/2004, establece en relación con la actualización de valores catastrales que: 1. Las leyes de presupuestos generales del Estado podrán actualizar los valores catastrales por aplicación de coeficientes, que podrán ser diferentes para cada clase de inmuebles. 2. Asimismo, las leyes de presupuestos generales del Estado podrán fijar coeficientes de actualización por grupos de municipios, que se determinarán en función de su dinámica inmobiliaria, de acuerdo con la clasificación de los mismos que se establezca reglamentariamente. Estos coeficientes se aplicarán sobre los valores catastrales actualizados conforme al apartado 1.

Finalmente, en la Disposición transitoria segunda relativa a la Valoración catastral de bienes inmuebles rústicos, se señala que lo establecido en el título II de esta ley (Ley de Catastro Inmobiliario) para la determinación del valor catastral queda en suspenso respecto a los bienes inmuebles rústicos hasta que mediante ley se establezca la fecha de su aplicación. 
Hasta ese momento, el valor catastral de los referidos bienes será el resultado de capitalizar al tres por ciento el importe de las bases liquidables vigentes para la exacción de la Contribución Territorial Rústica y Pecuaria correspondiente al ejercicio 1989, obtenidas mediante la aplicación de los tipos evaluatorios de dicha Contribución, prorrogados en virtud del Real Decreto Ley 7/1988, de 29 de diciembre, o de los que se hayan aprobado posteriormente en sustitución de ellos, y sin perjuicio de su actualización anual mediante los coeficientes establecidos y los que establezcan las Leyes de Presupuestos Generales del Estado, una vez incorporadas las alteraciones catastrales que hayan experimentado o experimenten en cada ejercicio.

Así pues, a la vista de todo lo anterior, no cabe duda de que los valores catastrales de los bienes inmuebles de naturaleza rústica se vienen actualizando y revisando continuamente, bien de forma directa, o a través de la Ley General de Presupuestos, y por tanto, las bases imponibles en el Impuesto sobre Bienes Inmuebles.

\section{EVOLUCIÓN DE LAS BASES IMPONIBLES EN EL IMPUESTO SOBRE BIENES INMUEBLES DE NATURALEZA RÚSTICA}

Tal y como se ha puesto de manifiesto en el apartado anterior del presente trabajo, las bases imponibles en el Impuesto sobre Bienes Inmuebles han venido actualizándose por aplicación de la normativa que le afecta a lo largo de los años en que este impuesto se viene aplicando. Lo que nos planteamos en este punto es cuantificar dichas actualizaciones para poder determinar la importancia de las mismas.

En el gráfico 1 se observa la evolución del valor catastral de los inmuebles de naturaleza rústica (en euros) por unidad de superficie (Hectárea) en el total nacional. Como puede observarse, el crecimiento del valor catastral ha sido continuo a lo largo de los 16 años incluidos en el gráfico, pasando de un valor cercano a los 200 €/Ha a otro próximo a los 550 €/Ha., lo que supone un incremento del $185 \%$ entre 1990 y 2005 (último año del que disponemos en las series históricas de la Dirección General del Catastro). Si analizamos este incremento de forma anual, podemos comprobar que salvo en 1991 en el que se produce un incremento del $55 \%$ respecto al valor catastral por hectárea de 1990, el resto de la serie mantiene unos incrementos anuales más o menos constantes, con un valor medio del 4,44\%, 
lo que resulta acorde con la actualización de los valores catastrales de los inmuebles de naturaleza rústica recogidos en la normativa analizada en el epígrafe anterior.

Gráfico 1. Evolución del valor catastral de los inmuebles de naturaleza rústica (en euros) por unidad de superficie (Hectárea).

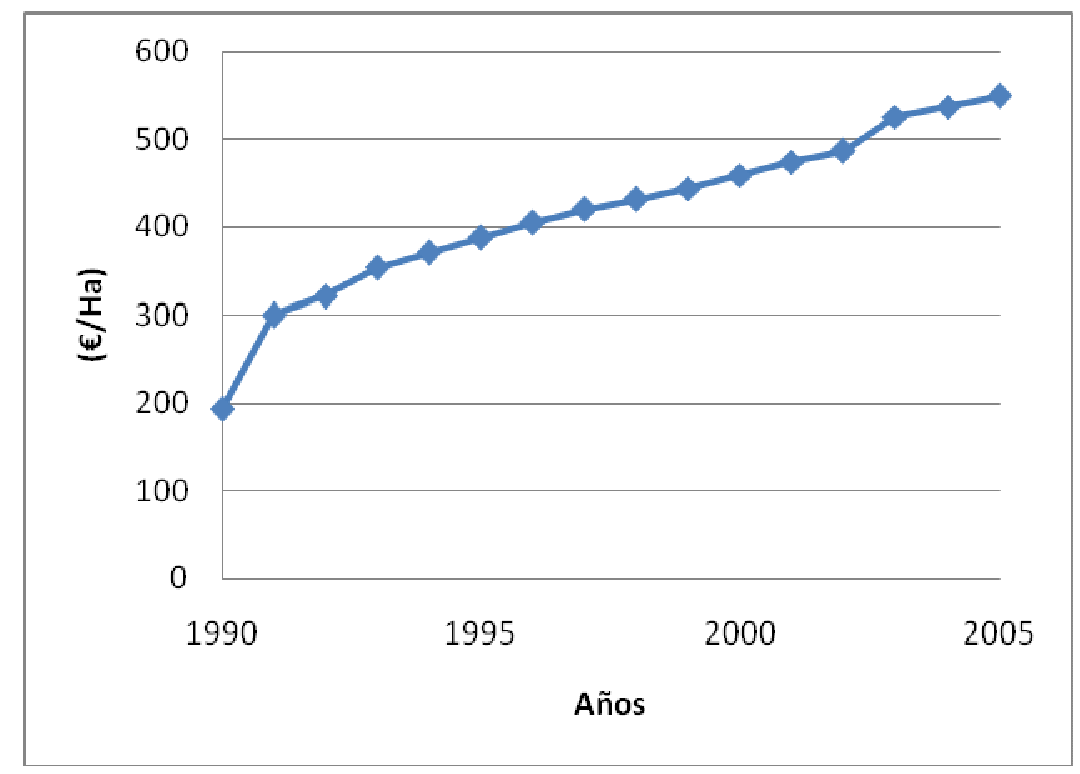

Fuente: Elaboración propia a partir de datos de la Dirección General del Catastro (2010).

El fuerte incremento registrado en el año 1991 tiene su justificación en la actualización de los valores catastrales de los inmuebles de naturaleza rústica que fijó la Ley 31/1990, de presupuestos general del Estado para 1991, que en su artículo 70 estableció que: "Uno. Para el período impositivo de 1991 los valores catastrales del Impuesto sobre Bienes Inmuebles serán los correspondientes al ejercicio de 1990, incrementados de la siguiente forma:

a) A los valores catastrales de los bienes inmuebles de naturaleza rústica se les aplicará un coeficiente de actualización del 50 por 100”

Llegados a este punto resulta imprescindible señalar que estas actualizaciones del valor catastral analizadas lo son, como ya se ha indicado, para el total de España. Sin embargo, es necesario estudiar si realmente representan una buena medida de lo que ha ocurrido en cada Comunidad Autónoma y en cada Municipio. Y ello a pesar de que la determinación del valor catastral no queda en manos de los Municipios, sino que es la Dirección General del Catastro la que debe fijar el valor catastral de de los bienes inmuebles que forman parte del correspondiente padrón municipal. Es por ello que cabría pensar que la 
actualización de esos valores debería ser lineal para todas las Comunidades Autónomas y Municipios. Sin embargo como podemos ver a continuación, esto no es así.

La tabla 1 muestra los resultados obtenidos para el incremento de los valores catastrales por unidad de superficie para el mismo período que el estudiado en el caso del total de España. No cabe duda que a la vista de los mismos la respuesta a la pregunta que nos hacíamos anteriormente es clara: la distribución geográfica de los incrementos en los valores catastrales de los bienes inmuebles de naturaleza rústica no es uniforme a lo largo de todo el territorio español.

Tabla 1. Incremento del valor catastral por unidad de superficie en el período 1990 - 2005 por Comunidad Autónoma.

\begin{tabular}{|l|c|}
\hline Comunidad & $\begin{array}{c}\text { Incremento Valor } \\
\text { catastral por Ha. (1990- } \\
\text { Autónoma }\end{array}$ \\
\hline Andalucía & $198 \%$ \\
\hline Aragón & $167 \%$ \\
\hline Asturias & $140 \%$ \\
\hline Baleares & $106 \%$ \\
\hline Canarias & $239 \%$ \\
\hline Cantabria & $153 \%$ \\
\hline Castilla La Mancha & $202 \%$ \\
\hline Castilla León & $176 \%$ \\
\hline Cataluña & $207 \%$ \\
\hline Comunidad & $162 \%$ \\
\hline Valenciana & $167 \%$ \\
\hline Extremadura & $200 \%$ \\
\hline Galicia & $162 \%$ \\
\hline La Rioja & $92 \%$ \\
\hline Madrid & $227 \%$ \\
\hline Murcia & \\
\hline
\end{tabular}

Fuente: Elaboración propia a partir de datos de la Dirección General del Catastro (2010). 
Como podemos comprobar, la variabilidad en las actualizaciones de los valores catastrales es más que notable, destacando en la parte baja la Comunidad de Madrid con un porcentaje de actualización del $92 \%$ y en la parte alta la Comunidad de Canarias con un porcentaje del 239\%, lo que supone una diferencia de 147 puntos porcentuales. Asimismo, en aquellas Comunidades Autónomas con un mayor peso del sector agrario en relación al Producto Interior Bruto, como son Extremadura, Castilla La Mancha y Castilla León, por citar algunas, los porcentajes de actualización son igualmente importantes, habiéndose prácticamente triplicado el valor catastral por hectárea en el período analizado.

El análisis realizado de variabilidad del porcentaje de actualización, puede repetirse del mismo modo a nivel de los municipios capitales de provincia, ocurriendo algo similar (tabla 2). El incremento porcentual medio en el período analizado se sitúa en el $158 \%$, pero con una desviación típica de 145 puntos porcentuales, lo que da una idea de la variabilidad de este incremento.

Tabla 2. Incremento del valor catastral por unidad de superficie en el período 1990 - 2005 por Municipio capital de provincia.

\begin{tabular}{|l|c|l|c|l|c|}
\hline Municipio & $\begin{array}{c}\text { Incremento } \\
\text { V.C. por Ha. } \\
\mathbf{( 1 9 9 0 - 2 0 0 5 )}\end{array}$ & Municipio & $\begin{array}{c}\text { Incremento } \\
\text { V.C. por Ha. } \\
\mathbf{( 1 9 9 0 - 2 0 0 5 )}\end{array}$ & \multicolumn{1}{|c|}{ Municipio } & $\begin{array}{c}\text { Incremento Valor } \\
\text { catastral por Ha. } \\
\mathbf{( 1 9 9 0 - 2 0 0 5 )}\end{array}$ \\
\hline Albacete & $345 \%$ & Huelva & $195 \%$ & $\begin{array}{l}\text { Palma de } \\
\text { Mallorca }\end{array}$ & $41 \%$ \\
\hline Alicante & $125 \%$ & Huesca & $107 \%$ & Pontevedra & $194 \%$ \\
\hline Almería & $286 \%$ & Jaén & $381 \%$ & Salamanca & $11 \%$ \\
\hline Ávila & $177 \%$ & La Coruña & $-58 \%$ & $\begin{array}{l}\text { Santa Cruz de } \\
\text { Tenerife }\end{array}$ & $169 \%$ \\
\hline Badajoz & $167 \%$ & $\begin{array}{l}\text { Las Palmas } \\
\text { de G. C. }\end{array}$ & $40 \%$ & Santander & $-25 \%$ \\
\hline Burgos & $79 \%$ & León & $8 \%$ & Segovia & $153 \%$ \\
\hline Cáceres & $81 \%$ & Lérida & $229 \%$ & Sevilla & $36 \%$ \\
\hline Cádiz & $863 \%$ & Logroño & $143 \%$ & Soria & $101 \%$ \\
\hline $\begin{array}{l}\text { Castellón de } \\
\text { la Plana }\end{array}$ & $83 \%$ & Lugo & $286 \%$ & Tarragona & $70 \%$ \\
\hline
\end{tabular}




\begin{tabular}{|l|c|l|c|l|c|}
\hline Ciudad Real & $432 \%$ & Madrid & $86 \%$ & Teruel & $164 \%$ \\
\hline Córdoba & $169 \%$ & Málaga & $105 \%$ & Toledo & $163 \%$ \\
\hline Cuenca & $178 \%$ & Murcia & $57 \%$ & Valencia & $183 \%$ \\
\hline Gerona & $273 \%$ & Orense & $129 \%$ & Valladolid & $71 \%$ \\
\hline Granada & $94 \%$ & Oviedo & $107 \%$ & Zamora & $99 \%$ \\
\hline Guadalajara & $217 \%$ & Palencia & $77 \%$ & Zaragoza & $111 \%$ \\
\hline
\end{tabular}

Fuente: Elaboración propia a partir de datos de la Dirección General del Catastro (2010).

A nivel de todos los municipios españoles los resultados son todavía mucho más llamativos. Nos encontramos desde municipios donde el valor catastral por hectárea incluso ha disminuido, a otros en los que ha aumentado más de un $1.000 \%$.

Otro de los aspectos a analizar es la disparidad que se produce en los valores catastrales por hectárea entre unas Comunidades Autónomas y otras (gráfico 2).

Gráfico 2. Evolución de los valores catastrales por hectárea para cada Comunidad Autónoma.

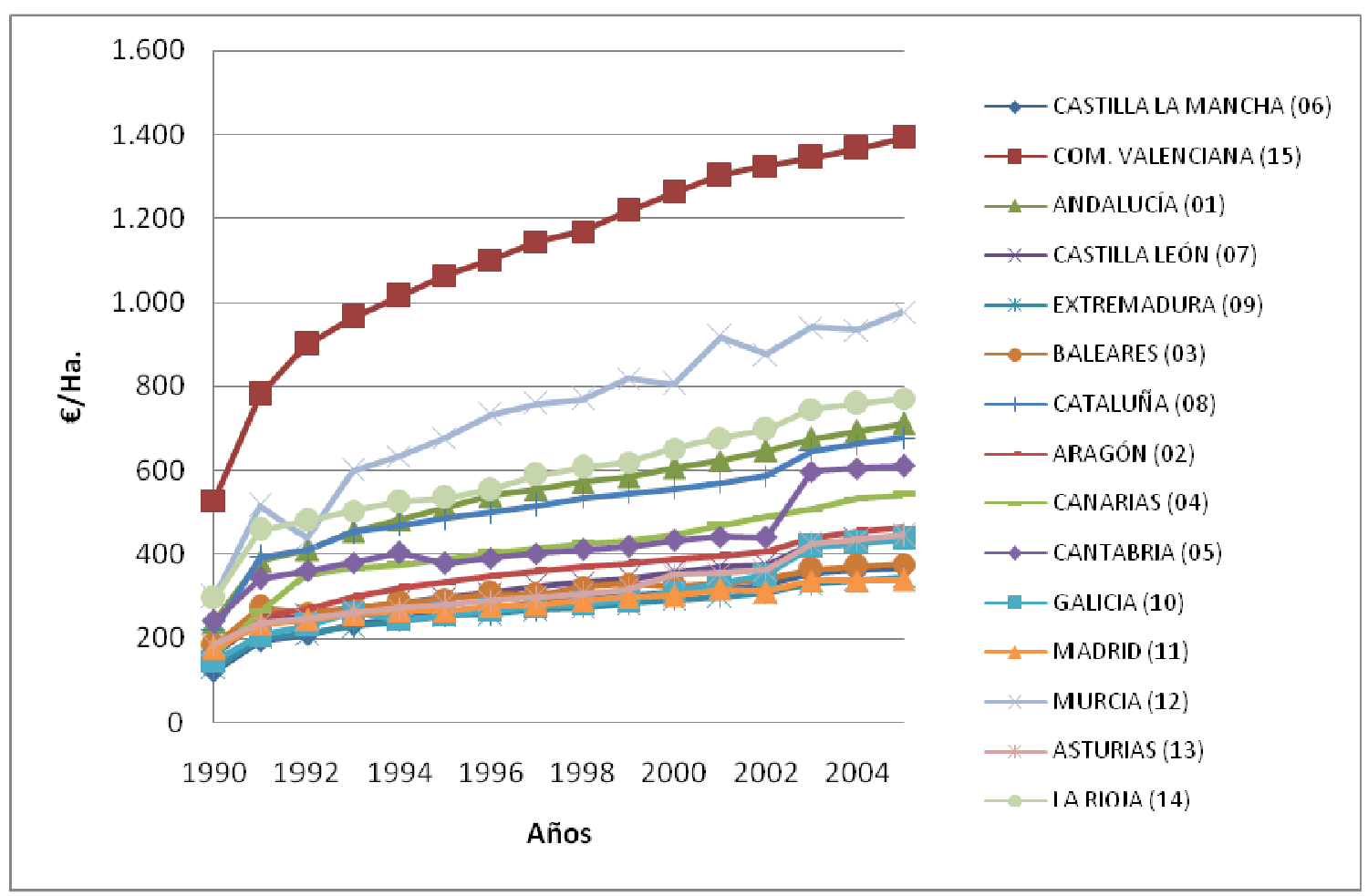

Fuente: Elaboración propia a partir de datos de la Dirección General del Catastro (2010). 
En el gráfico 2 podemos observar como los valores catastrales por hectárea en el caso de la Comunidad Valenciana son muy superiores a los del resto de Comunidades Autónomas para todos los años analizados, situándose en el extremo contrario la Comunidad de Madrid o Extremadura. La diferencia llega a cuadruplicarse en el caso del año 2005. No obstante, aunque con las diferencias ya señaladas anteriormente, la evolución del incremento de los valores catastrales es constante en todas las Comunidades Autónomas, observándose un crecimiento continuo del mismo a lo largo del todo el período. Cabe señalar el caso de Cantabria que en el año 2003 se produce un repunte del valor catastral por hectárea de casi un $36 \%$ respecto a 2002. El caso de Murcia también resulta curioso por cuanto su crecimiento a lo largo de los años es más errático que el del resto.

No obstante, en principio esta gran disparidad de valores debería deberse a modificaciones de las características de los bienes inmuebles de naturaleza rústica que conforman los padrones municipales, como puede ser la alteración en los aprovechamientos de los mismos, por ejemplo, por cambios en los cultivos.

En cualquier caso, los resultados obtenidos obligan a cuestionarnos la utilización de un criterio como este en una normativa de ámbito estatal como la que aquí estamos analizando, pues puede implicar consecuencias importantes (la pérdida de la especial protección) entre una cooperativa y otra por el simple hecho de estar en Comunidades Autónomas diferentes, o incluso en localidades diferentes.

\section{CONCLUSIONES}

La limitación en las bases imponibles en el IBI de los socios de cooperativas agrarias calificadas como especialmente protegidas se justificaba en la necesidad de asegurar que los socios de las cooperativas a las que se otorgaba una especial protección fueran pequeños agricultores.

Así, para el total nacional, con un valor catastral medio en 1990 de 193 €/Ha., la dimensión máxima de la explotación del agricultor para cumplir ese límite se cifraba en 202 Ha. En 2005, con un valor catastral de 549 €/Ha., esta dimensión se reduce a 71 Ha. Estas extensiones, en determinadas Comunidades Autónomas son aún más pequeñas, como el caso 
extremo de la Comunidad Valenciana donde se pasa de una dimensión media de 74 Ha. en 1990 a otra de 28 Ha. en 2005.

Esto es, en una coyuntura económica en la que se hace necesario en general una mayor dimensión empresarial (a todos los niveles), nos encontramos con una normativa que no hace sino exigir cada vez menores dimensiones de los socios de la cooperativa agraria, si no quiere perder su especial protección.

Ante esto, parece necesario revisar la limitación en las bases imponibles en el IBI de los socios de cooperativas agrarias fijado en 39.065,79€.

Y la revisión señalada, entendemos que puede hacerse en una doble dirección: bien eliminando directamente el límite en las bases imponibles en el IBI de los socios; o bien actualizando dicho límite. En ambos casos con el objetivo de poder mantener la calificación como especialmente protegida de una cooperativa agraria de la que no habrían cambiado sustancialmente las magnitudes que la caracterizan, más allá del simple paso del tiempo.

La primera de las direcciones apuntadas, esto es, la eliminación del límite en las bases imponibles en el IBI de los socios para la calificación como especialmente protegida de una cooperativa agraria, creemos que se justifica por la aleatoriedad que se produce en los valores catastrales de los bienes de naturaleza rústica en las diferentes Comunidades Autónomas y en los diferentes municipios, aunque estos vengan motivados por los diferentes aprovechamientos agrarios de estos inmuebles. Esto, como se ha señalado, provoca grandes diferencias en las bases imponibles en el IBI de los agricultores, lo que podría implicar el incumplimiento para una cooperativa ubicada en un determinado municipio del límite fijado para las bases imponibles de sus socios en el IBI, y por tanto la pérdida de la especial protección, cuando justo en el municipio de al lado, otra cooperativa con socios con incluso explotaciones de mayor dimensión, no tendrían problema para cumplir con el límite comentado.

A nuestro juicio, esto podría contravenir el principio de igualdad que propugna nuestro ordenamiento constitucional. Y por tanto, quedaría justificada la supresión del límite en las bases imponibles en el IBI de los socios para la calificación como especialmente protegida de una cooperativa agraria. 
Pero más allá de eso, y como una justificación adicional a su eliminación, también podríamos plantearnos el porqué la especial protección de una cooperativa agraria debe depender del IBI de sus socios, que en definitiva es algo externo a ellas. La tendencia en otros países europeos (Francia, Italia, Alemania, entre otros) es sustituir esta condición por otra de carácter interno, como el nivel de mutualidad, esto es, el porcentaje de operaciones con socios. No cabe duda que esta solución implica un cambio más profundo de la Ley de Régimen Fiscal de Cooperativas, que tal vez no esté muy lejana.

La segunda de las direcciones apuntadas es, como hemos señalado, la actualización del límite fijado en las bases imponibles en el IBI de los socios para la calificación como especialmente protegida de una cooperativa agraria.

Ha quedado demostrado empíricamente en este trabajo que los valores catastrales de los bienes de naturaleza rústica han venido sufriendo una continua actualización desde la aprobación de la LRFC en el año 1990 y hasta el último año disponible en las estadísticas de la Dirección General del Catastro, 2005, sin que el límite de las bases imponibles en el IBI de los agricultores se haya modificado.

Resulta curioso además en este punto, que precisamente un año después de la aprobación de la LRFC se produjera una actualización muy importante de los valores catastrales de los inmuebles de naturaleza rústica, que para el total nacional se cifra en más del 55\%. Este incremento se fijó, como hemos visto, en la Ley 31/1990, de presupuestos general del Estado para 1991.

Sin embargo, el legislador consciente de las consecuencias que este fuerte incremento podía tener en el cumplimiento de determinados límites relacionados con esa valoración, incluyó en ese mismo artículo que aprobaba dicho incremento que: "El incremento de los valores catastrales de naturaleza rústica previsto en el párrafo anterior no tendrá efectos respecto al límite de base imponible de las explotaciones agrarias que condiciona la inclusión en el Régimen Especial Agrario de la Seguridad Social de los trabajadores por cuenta propia”. 
Pero se olvidó de excluir también de sus efectos a las cooperativas agrarias, con lo que se genera de nuevo una situación de trato desigual.

Es por ello, que a nuestro juicio son dos las posibilidades que se plantean para responder a la línea de actualización del límite de bases imponibles en el IBI fijado por la LRFC: O bien dejar sin aplicación los incrementos en la valoración catastral de los bienes de naturaleza rústica desde 1990 de cara a determinar el límite en la base imponible del IBI de los socios de las cooperativas agrarias para su calificación de especialmente protegida; $\mathrm{O}$ bien, actualizar el límite fijado de 39.065,79 € conforme al incremento experimentado por el valor catastral desde la aprobación de la LRFC.

No cabe duda que la primera de las opciones tiene una serie de dificultades añadidas de carácter técnico que hace que no sea la más recomendable. ¿Cuál sería el valor catastral de las explotaciones de los socios en el año 1990? Probablemente, aunque sí fuera posible determinarlo, las dificultades para obtenerlos podrían generar situaciones de mayores desequilibrios.

Por tanto, parece mucho más operativa la segunda de las propuestas. No tendríamos más que determinar el incremento experimentado en el valor catastral de los inmuebles de naturaleza rústica y aplicarlo al límite fijado en la LRFC. Así, tal y como hemos estimado en el presente trabajo, este incremento para el período 1990 - 2005 se ha cifrado como media a nivel nacional en el 184,13\%. Dado que desde 2005 hasta la actualidad han seguido incrementándose los valores catastrales, pero no contamos con la información de la Dirección General del Catastro para cuantificarlos, entendemos adecuado utilizar como tasa de actualización el incremento medio anual que se ha producido en el período analizado (exceptuando el incremento de 1991) que se sitúa en el 4,44\%.

Con esto, el nuevo límite para las bases imponibles del IBI de los socios de las cooperativas agrarias para su calificación de especialmente protegida, debería establecerse próximo a los $90.000 €$.

En cualquier caso con esta opción podrían seguir existiendo situaciones anómalas puesto que, como ya hemos señalado, el incremento en los valores catastrales no ha sido el mismo para todos los municipios. 


\section{BIBLIOGRAFÍA}

GARCÍA CALVENTE, Y., GARIJO, M.R. (2005). Cooperativas. Régimen tributario actual en el ordenamiento español. En CALVO ORTEGA, R. (Director). Fiscalidad de las entidades de economía social. Navarra. Ed. Thomson Civitas, 2005, p. 723, ISBN 84470-2354-0.

DE LUÍS ESTEBAN, J.M.. Presente y futuro de la fiscalidad de las cooperativas. Ciriec España. Revista de Economía Pública, Social y Cooperativa, $\mathrm{n}^{\circ}$ extraordinario, octubre 1987, pp. 129-151.

DIRECCIÓN GENERAL DEL CATASTRO. Estadísticas catastrales. En http://www.catastro.meh.es/esp/estadistica/estadisticas2.asp . Mayo 2010.

JULIÁ IGUAL J.F., SERVER IZQUIERDO R.J.. Fiscalidad de cooperativas: Teoría y Práctica. $3^{\text {a }}$ edición. Madrid. Ed. Pirámide. 1996, p. 326, ISBN 84-368-1058-9.

JULIA IGUAL, J.F., SERVER IZQUIERDO R.J., MARÍN SÁNCHEZ M.M.. Gestión fiscal en la empresa. Valencia. Ed. Servicio Publicaciones Universidad Politécnica de Valencia. 1999, p. 276, ISBN 84-7721-762-9.

MARÍ VIDAL, S., JULIÁ IGUAL J.F., 2001. Evolución del cooperativismo agrario en España. De los sindicatos agrícolas a la actualidad. REVESCO. Revista de Estudios Cooperativos, $\mathrm{n}^{\circ} 73,1^{\circ}$ Cuatrimestre, 2001, p. 59-80.

MAS ORTIZ, A., CINTADO CANTO F.J., 2007. La empresa agraria y el impuesto sobre sociedades. Régimen fiscal de las cooperativas agrarias y de las sociedades agrarias de transformación. En ROMERO GARCÍA F. (Coordinador). La fiscalidad de la agricultura y la ganadería. Valencia. Ed. Fiscal CISS, 2007, p. 508, ISBN 978-84-8235597-9.

\section{Referencias legales.}

Ley 20/1990 del Régimen Fiscal de Cooperativas.

Ley 31/1990, de presupuestos general del Estado para 1991.

Real Decreto Legislativo 1/2004 por el que se aprueba el Texto Refundido de la Ley del Catastro Inmobiliario. 
Real Decreto Legislativo 2/2004 de 5 de marzo, por el que se aprueba el texto refundido de la Ley Reguladora de las Haciendas Locales.

Ley 24/2005 de reformas para el impulso a la productividad.

Decisión de la Comisión de 15 de Diciembre de 2009 relativa a las medidas de apoyo al sector agrícola aplicadas por España tras la subida del coste del combustible. 